carrier concentration as a function of temperature do not seem to be available.

We wish to express our thanks to Mr. N. A. C. Thompson for the use of his experimental results. Acknowledgment is made to the Admiralty for per. mission to publish this communication.

$$
\begin{aligned}
& \text { J. W. Allen } \\
& \text { R. J. CherRy }
\end{aligned}
$$

Services Electronics Research Laboratory,

$$
\text { Baldock, Herts. }
$$

1 Mott, N. F.; and Gurney, R. W., "Electronic Processes in Ionic Crystals"'(Oxford, 1940).

Smith, R. W., and Rose, A., Phys. Rev., 97, 1531 (1955)

Allen, J. W., Nature, 187, 403 (1960).

' Lampert, M. A., Phys. Rev., 108, 1648 (1956).

\section{Hyperfine Splitting of Rubidium-87}

RUBIDIUM has been used in the development of gas cell frequency standards, and from measurements of the variation of frequency with the pressure of the buffer gas used in the cell it has been deduced ${ }^{1}$ that the frequency corresponding to zero gas pressure is :

$$
6834682608 \text { c./s. } \pm 7 \text { c./s. }
$$

where the second of time is that giving 9192631770 c./s. for the cæsium hyperfine structure splitting at zero field ${ }^{2}$. It has been found, however, that when cæsium is used in a gas cell the extrapolated frequency is $30 \mathrm{c} . / \mathrm{s}$. lower than the value given above obtained by an atomic beam experiment ${ }^{3}$. There is therefore considerable interest in the atomic beam value for rubidium. For this purpose the oven of the long beam chamber at the National Physical Laboratory was filled with a mixture of rubidium-87 and crsium-133. A strong beam of atoms was obtained at an oven temperature of $120^{\circ} \mathrm{C}$., and the application of the appropriate radio frequency produced, alternatively, resonances of the rubidium or cæsium atoms. The amplitude of the cæsium resonance was 50 per cent greater than that of rubidium, the higher vapour pressure of cæsium presumably compensating for the fact that a greater proportion of the rubidium atoms take part in the resonance. In both cases the signal to noise ratio was adequate for the precise measurement of the frequencies corresponding to the resonance peaks. The rubidium resonanee, which was 71 c./s. wide, was excited in cavities independently tuned and separated by a distance of $254 \mathrm{~cm}$. It was slightly asymmetrical, but the asymmetry was measured and a correction applied. The value on the atomic time-scale corrected for the asymmetry and magnetic field is :

$$
6834682614 \cdot 0 \pm 1 \text { c./s. }
$$

It is proposed to continue measurements of the two atomic transition frequencies.

This communication is published by permission of the Director of the Laboratory.

\section{Essen \\ E. G. Hope \\ D. SUTCLIFEE}

National Physical Laboratory, Teddington, Middlesex.

1 Bender, P. L., Beaty, E. C., and Chi, A. R., Phys. Rev. Letters, 1. 311 (1958),

${ }^{2}$ Markowitz, Wm., Hall, R. G., Essen, L., and Parry, J. V. L., Phys. Rev. Letters, 1, 105 (1958)

${ }^{3}$ Beaty, E. C., Bender, P. L., and Chi, A. R., Phys. Rev., 112, 450 (1958).

4 Essen, L., and Parry, J. V. L., Nature, 184, 1791 (1959).

\section{Whisker Growth from Quartz}

WHISKER growth and associated phenomena have been extensively reviewed recently by Messrs. N. F. R. Nabarro and P. J. Jackson ${ }^{1}$. They cited observations of growth from metallic oxides, sulphides and hydroxides along with the more usual growth in metals. Whisker growth from fused quartz, apparently an unreported phenomenon, is unusual due to the vitreous nature of the substrate.

The whiskers are shown in Fig. 1. Large single whiskers and clusters of shorter ones grew from discrete places on the substrate. The quartz was heated in a 'Zirco' tube through which flowed 1 litre/ min. of dry nitrogen. 'The temperature was approximately $1,425^{\circ} \mathrm{C}$. and time for the growth was $24 \mathrm{hr}$. Immediately adjacent to the whiskers was a dense patch of pine tree-like dendrites. The whiskers ranged in length from millimetre to micron size.
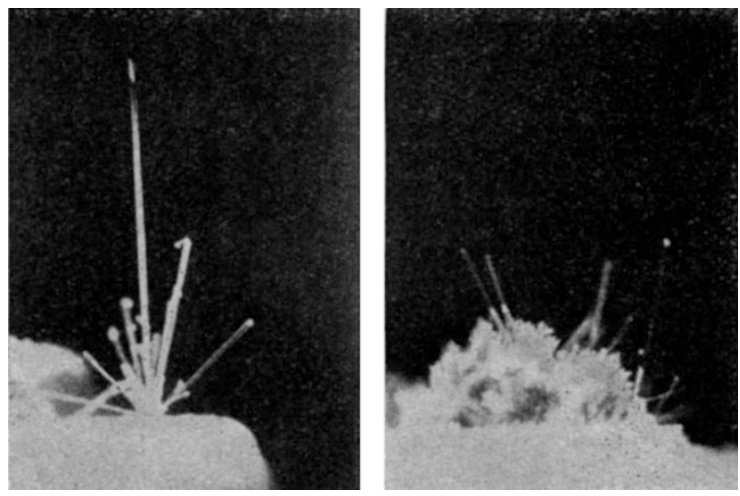

Fig. 1. Quartz whiskers. ( $\times 15)$

The quartz substrate from which these whiskers grew had a skin of devitrified quartz covering its surface due to regular use at elevated temperatures. There was silicon material placed on the substrate near the growth area. There is no apparent evidence to point to how the whiskers grew either from the base or at the tip. However, the devitrified skin afforded the conditions for nucleation.

Further work and mechanical tests will be undertaken on these whiskers.

\section{R. J. JACCODINE}

R. K. KIINE

Bell Telephone Laboratories, Incorporated, Allentown,

Pennsylvania.

Proc. Int. Conf. Crystal Growth, 13 (J. Wiley and Sons, 1958).

\section{Simple Methods for preparing Pointed Filaments for the Electron Microscope}

THE performance of electron guns used in the electron microscope has been studied by Haine and Einstein ${ }^{1}$, Boersch and Born ${ }^{2}$, and others. The present indications are that pointed filaments improve this performance. The first of these filaments was prepared by $\mathrm{Hibi}^{3}$ by hand-polishing or etching a short length of tungsten wire which was welded or otherwise attached to a conventional hairpin filament according to Müller's method4. Heating was obtained by conduction from the hairpin. 